\title{
A NEW TOPOLOGY OF HYBRID MULTI LEVEL INVERTER WITH EQUAL AREA CRITERIA SWITCHING TECHNIQUE
}

\author{
Palemkota Mahesh $^{1}$, H R Ramesh ${ }^{2}$ \\ ${ }^{1} P G$ Scholar (Power Electronics), Department of Electrical Engineering, UVCE - BANGALORE \\ mahee230555@gmail.com \\ ${ }^{2}$ Associate Professor, Department of Electrical Engineering, UVCE - BANGALORE \\ nayaka.ramesh@yahoo.com
}

\begin{abstract}
In this paper, a new multi level inverter (MLI) is introduced. This paper mainly focusing on reduction of Total Harmonic Distortion (THD). By adding one step voltage to the conventional MLI to increase number of levels without increasing the number of switches and to achieve minimum THD with simple switching technique called equal area criteria (EAC). A 33-level MLI is implemented and simulated using MATLAB/simulink. Simulation was done with resistive load and results shown.
\end{abstract}

Keywords: Multi Level Inverter (MLI), Total Harmonic Distortion (THD), Equal Area Criteria (EAC).

\section{INTRODUCTION}

There are so many MLI topologies are proposed. In conventional H-bridge and hybrid type multi level inverter, it requires more number of switches to get required number of levels [1]. But in proposed type MLI with eight switches we can get 33-levels without increasing number of switches by adding one step voltage to the conventional MLI the number of levels get increase. We know when the number of switches is more the overall efficiency of the inverter is reduces and the control circuit becomes complex. The proposed MLI will overcome these difficulties. Up to now there are so many switching techniques are proposed. Even though we have different switching techniques [2] the best way to reduce the lower order harmonic effect on fundamental wave is selective harmonic elimination (SHE). In this paper, we are introducing a new MLI topology for getting IEEE standard (519-1992) THD without increasing the number of switches for 33-level. Using this technique we have two ways to get switching angles [3]. One is mathematical approach, by solving non-linear equations by iterative manner. And second approach is MATLAB program based, in this we have two methods, NewtonRapson (NR) [4] and Genetic Algorithm (GA) [5]. But in NR method finding initial switching angles is a challenging one. And in GA we no need to find initial angles, but the length of the program is more and required more number of iterations. To overcome the above difficulties, the simple switching technique called equal area criteria (EAC) is implemented and is a one of the lower order harmonic elimination technique.

\section{NEW TOPOLOGY}

With asymmetrical voltage sources and combination of level generating and polarity generating cells the new MLI constructed. The proposed MLI is as shown below,

$* * *$

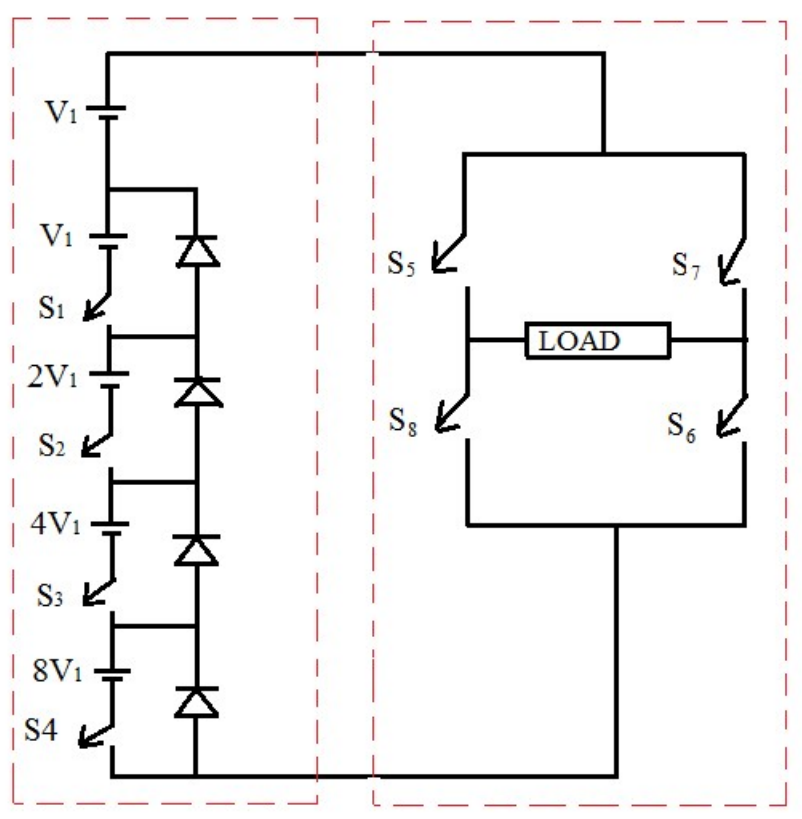

Level generating cell Polarity generating cell

Fig.1. Proposed 33-level MLI with asymmetrical sources

Here, the voltage $\mathrm{V}_{1}$ is step voltage and the voltage ratio of asymmetrical sources is shown below,

$$
\mathrm{V}_{1}: \mathrm{V}_{1}: 2 \mathrm{~V}_{1}: 4 \mathrm{~V}_{1}: 8 \mathrm{~V}_{1}
$$

Here we have two cells, the LGC generates number of output levels with the help of switching sequence and PGC generates $+\mathrm{Ve}$ and $-\mathrm{Ve}$ half waves for $\mathrm{AC}$ operation. The voltage across LGC is 33-level DC and the frequency of voltage wave is two times of output voltage frequency. 


\section{SWITCHING TECHNIQUE}

Even though we have so many switching techniques among all, the best way to get minimum THD is selective harmonic elimination (SHE). By solving non-linear equations is given below,

$$
\left\{\begin{array}{l}
\frac{4 V d c}{\pi}\left(\cos \left(\theta_{1}\right)-\cos \left(\theta_{2}\right) \ldots+\cos \left(\theta_{N}\right)\right)=V_{F} \\
\cos \left(5 \theta_{1}\right)-\cos \left(5 \theta_{2}\right) \ldots+\cos \left(5 \theta_{N}\right)=0 \\
\cos \left(7 \theta_{1}\right)-\cos \left(7 \theta_{2}\right) \ldots+\cos \left(7 \theta_{N}\right)=0 \\
\cdots \ldots \\
\cos \left(m O_{1}\right)-\cos \left(m O_{2}\right) \ldots+\cos \left(m O_{N}\right)=0
\end{array}\right.
$$

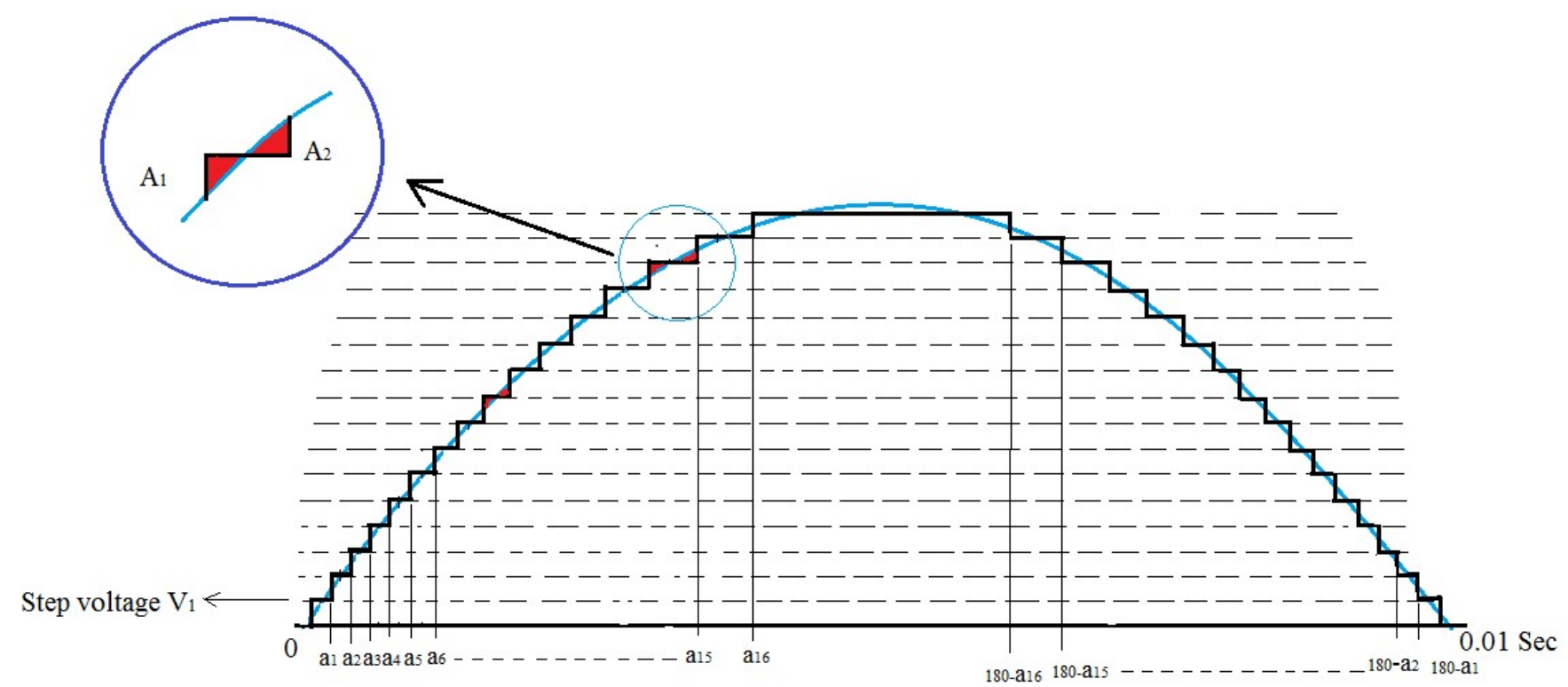

Fig. 2. Equal Area Criteria (EAC) switching technique

Here, $A_{1}$ and $A_{2}$ are the areas shown in above figure. To get minimum THD the areas of $\mathrm{A}_{1}$ and $\mathrm{A}_{2}$ should be equal. The fundamental switching frequency is taken as $50 \mathrm{~Hz}$. The step voltage is a minimum voltage that presented in level generation circuit (LGC). $a_{1}, a_{2}, a_{3}, \ldots a_{n}$ are the switching angles for N-level MLI. The angles should be $<90^{\circ}$.

$$
0<\mathbf{a}_{1}<\mathbf{a}_{2}<\mathbf{a}_{3}<\mathbf{a}_{4}<\mathbf{a}_{5}<\mathbf{a}_{6}<\mathbf{a}_{7}---\mathbf{a}_{\mathbf{n}}<90^{0}
$$

Number of switching angles for N-levels $=[$ (Number of levels-1)/2]

Mathematical formula for angle calculation:

$\mathrm{N}^{\text {th }}$ switching angle $\mathrm{a}_{\mathrm{n}}($ deg. $)=$

[[Time at which the $\mathrm{N}^{\text {th }}$ level vertical line touches the time axis (x-axis) $] *[2 *$ fundamental frequency $]] * 180^{\circ}$

By using above mathematical formula for $\mathrm{N}$-number of levels the switching angles we can easily calculate.
Finding angles by solving the above non-linear equations is possible if levels are less but in it is very difficult when levels are more and time consuming. These types of equations can be solve with the help of MATLAB program using any of the above programming based techniques. The simple technique EAC is implemented to find initial values and these initial switching angles will give minimum THD for any number of levels. The EAC is a natural method of find best switching angles [6].

\section{Equal Area Criteria:}

By this EAC method we can find the best switching angles for the switches, by dividing half of fundamental sine wave by horizontally and vertically with step voltage and time (ms) respectively.
The switching angles for 33-levels are given below,

$\mathrm{a} 1=1^{0}, \mathrm{a} 2=4^{0,} \mathrm{a} 3=7^{0}, \mathrm{a} 4=11^{0}, \mathrm{a} 5=15^{0}, \mathrm{a} 6=18^{0}, \mathrm{a} 7=22^{0}$, $\mathrm{a} 8=26^{0}, \mathrm{a} 9=31^{0}, \mathrm{a} 10=34^{0}, \mathrm{a} 11=40^{0}, \mathrm{a} 12=44^{0}, \mathrm{a} 13=49^{0}$, $\mathrm{a} 14=55^{0}, \mathrm{a} 15=63^{0}, \mathrm{a} 16=73^{0}$

The above switching angles used to turn $\mathrm{ON}$ the power switches at that angle. The sinusoidal pulse width modulation technique (SPWM) is used for controlling $\mathrm{H}$ bridge switches as shown below [7].

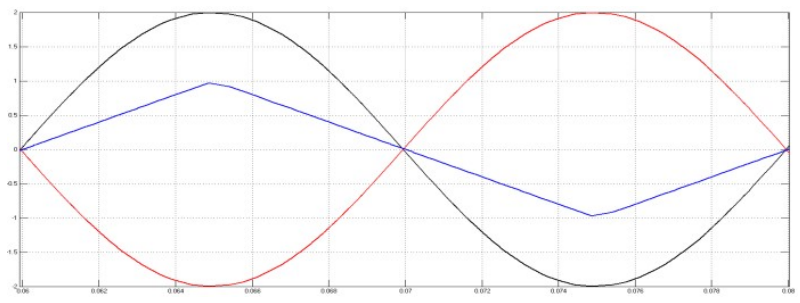

Fig.3. SPWM for H-bridge 
IV. SWITCHING TABLE FOR 33-LEVELS

\begin{tabular}{|c|c|c|c|c|c|c|c|c|c|}
\hline S. NO & $\mathrm{S} 1$ & S2 & $\mathrm{S} 3$ & $\mathrm{~S} 4$ & S5 & S6 & S7 & S8 & LEVEL \\
\hline 1 & 1 & 1 & 1 & 1 & 1 & 1 & 0 & 0 & $16 \mathrm{~V} 1$ \\
\hline 2 & 0 & 1 & 1 & 1 & 1 & 1 & 0 & 0 & $15 \mathrm{~V} 1$ \\
\hline 3 & 1 & 0 & 1 & 1 & 1 & 1 & 0 & 0 & $14 \mathrm{~V} 1$ \\
\hline 4 & 0 & 0 & 1 & 1 & 1 & 1 & 0 & 0 & $13 \mathrm{~V} 1$ \\
\hline 5 & 1 & 1 & 0 & 1 & 1 & 1 & 0 & 0 & $12 \mathrm{~V} 1$ \\
\hline 6 & 0 & 1 & 0 & 1 & 1 & 1 & 0 & 0 & $11 \mathrm{~V} 1$ \\
\hline 7 & 1 & 0 & 0 & 1 & 1 & 1 & 0 & 0 & $10 \mathrm{~V} 1$ \\
\hline 8 & 0 & 0 & 0 & 1 & 1 & 1 & 0 & 0 & $9 \mathrm{~V} 1$ \\
\hline 9 & 1 & 1 & 1 & 0 & 1 & 1 & 0 & 0 & $8 \mathrm{~V} 1$ \\
\hline 10 & 0 & 1 & 1 & 0 & 1 & 1 & 0 & 0 & $7 \mathrm{~V} 1$ \\
\hline 11 & 1 & 0 & 1 & 0 & 1 & 1 & 0 & 0 & $6 \mathrm{~V} 1$ \\
\hline 12 & 0 & 0 & 1 & 0 & 1 & 1 & 0 & 0 & $5 \mathrm{~V} 1$ \\
\hline 13 & 1 & 1 & 0 & 0 & 1 & 1 & 0 & 0 & $4 \mathrm{~V} 1$ \\
\hline 14 & 0 & 1 & 0 & 0 & 1 & 1 & 0 & 0 & $3 \mathrm{~V} 1$ \\
\hline 15 & 1 & 0 & 0 & 0 & 1 & 1 & 0 & 0 & $2 \mathrm{~V} 1$ \\
\hline 16 & 0 & 0 & 0 & 0 & 1 & 1 & 0 & 0 & 1V1 \\
\hline 17 & 0 & 0 & 0 & 0 & 0 & 1 & 0 & 1 & 0V1 \\
\hline 18 & 0 & 0 & 0 & 0 & 0 & 0 & 1 & 1 & $-1 \mathrm{~V} 1$ \\
\hline 19 & 1 & 0 & 0 & 0 & 0 & 0 & 1 & 1 & $-2 \mathrm{~V} 1$ \\
\hline 20 & 0 & 1 & 0 & 0 & 0 & 0 & 1 & 1 & $-3 \mathrm{~V} 1$ \\
\hline 21 & 1 & 1 & 0 & 0 & 0 & 0 & 1 & 1 & $-4 \mathrm{~V} 1$ \\
\hline 22 & 0 & 0 & 1 & 0 & 0 & 0 & 1 & 1 & $-5 \mathrm{~V} 1$ \\
\hline 23 & 1 & 0 & 1 & 0 & 0 & 0 & 1 & 1 & $-6 \mathrm{~V} 1$ \\
\hline 24 & 0 & 1 & 1 & 0 & 0 & 0 & 1 & 1 & $-7 \mathrm{~V} 1$ \\
\hline 25 & 1 & 1 & 1 & 0 & 0 & 0 & 1 & 1 & $-8 \mathrm{~V} 1$ \\
\hline 26 & 0 & 0 & 0 & 1 & 0 & 0 & 1 & 1 & $-9 \mathrm{~V} 1$ \\
\hline 27 & 1 & 0 & 0 & 1 & 0 & 0 & 1 & 1 & $-10 \mathrm{~V} 1$ \\
\hline 28 & 0 & 1 & 0 & 1 & 0 & 0 & 1 & 1 & $-11 \mathrm{~V} 1$ \\
\hline 29 & 1 & 1 & 0 & 1 & 0 & 0 & 1 & 1 & $-12 \mathrm{~V} 1$ \\
\hline 30 & 0 & 0 & 1 & 1 & 0 & 0 & 1 & 1 & $-13 \mathrm{~V} 1$ \\
\hline 31 & 1 & 0 & 1 & 1 & 0 & 0 & 1 & 1 & $-14 \mathrm{~V} 1$ \\
\hline 32 & 0 & 1 & 1 & 1 & 0 & 0 & 1 & 1 & $-15 \mathrm{~V} 1$ \\
\hline 33 & 1 & 1 & 1 & 1 & 0 & 0 & 1 & 1 & $-16 \mathrm{~V} 1$ \\
\hline
\end{tabular}




\section{SIMULATION RESULTS}

Hybrid MLI simulation circuit with resistive load is as shown below

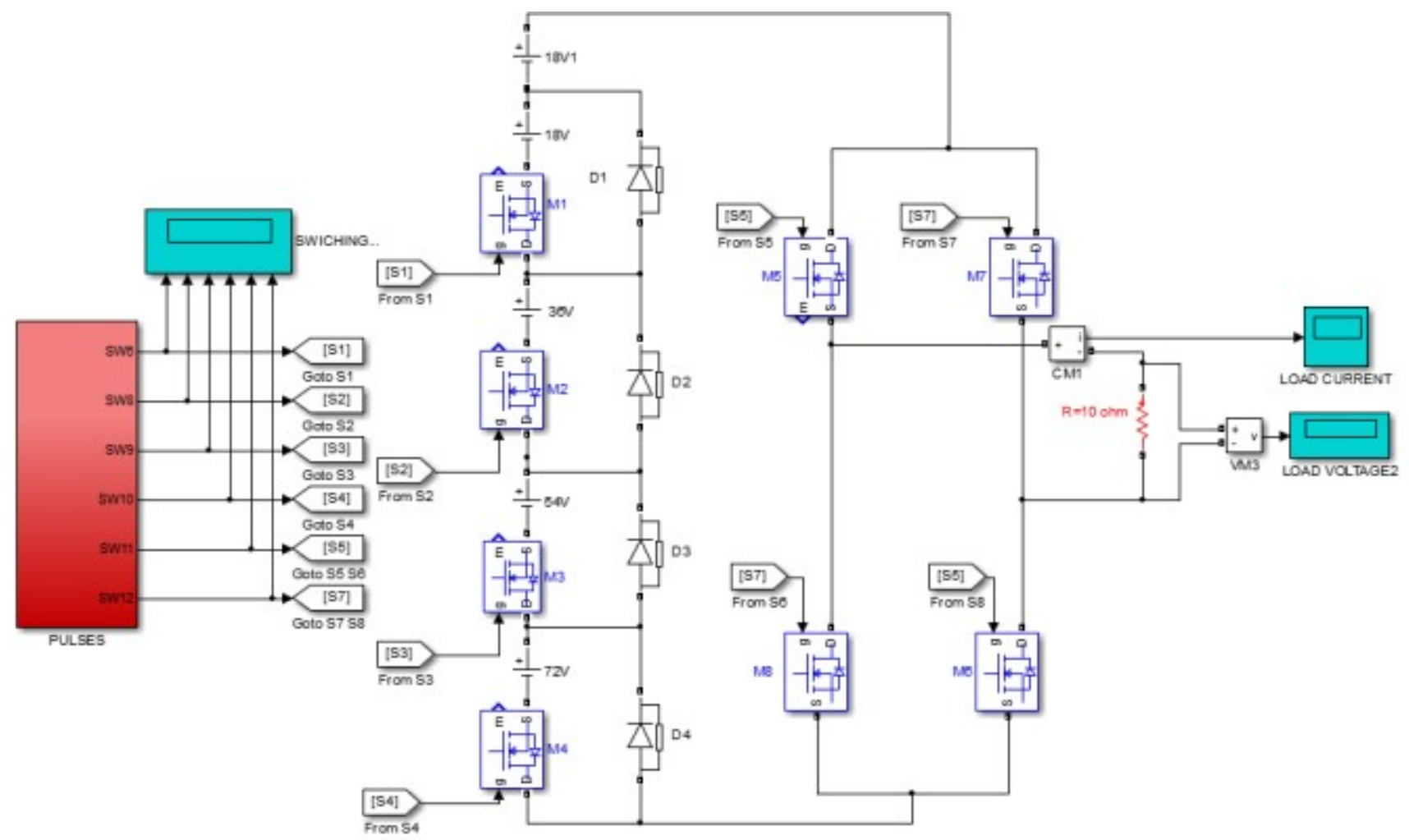

Fig.4. Simulation circuit of proposed Hybrid 33- level inverter

After calculation of switching angles we used pulse generators for LGC to Switch ON the switches at calculated switching angles and for H-bridge SPWM [8], [9]. We achieved the THD within the IEEE standards and is observed with the help of FFT analysis using MATLAB/simulink software for 33-levels [10], [11]. The THD is $2.55 \%$ with resistive load of $100 \mathrm{ohms}$. The output voltage waveforms are shown.

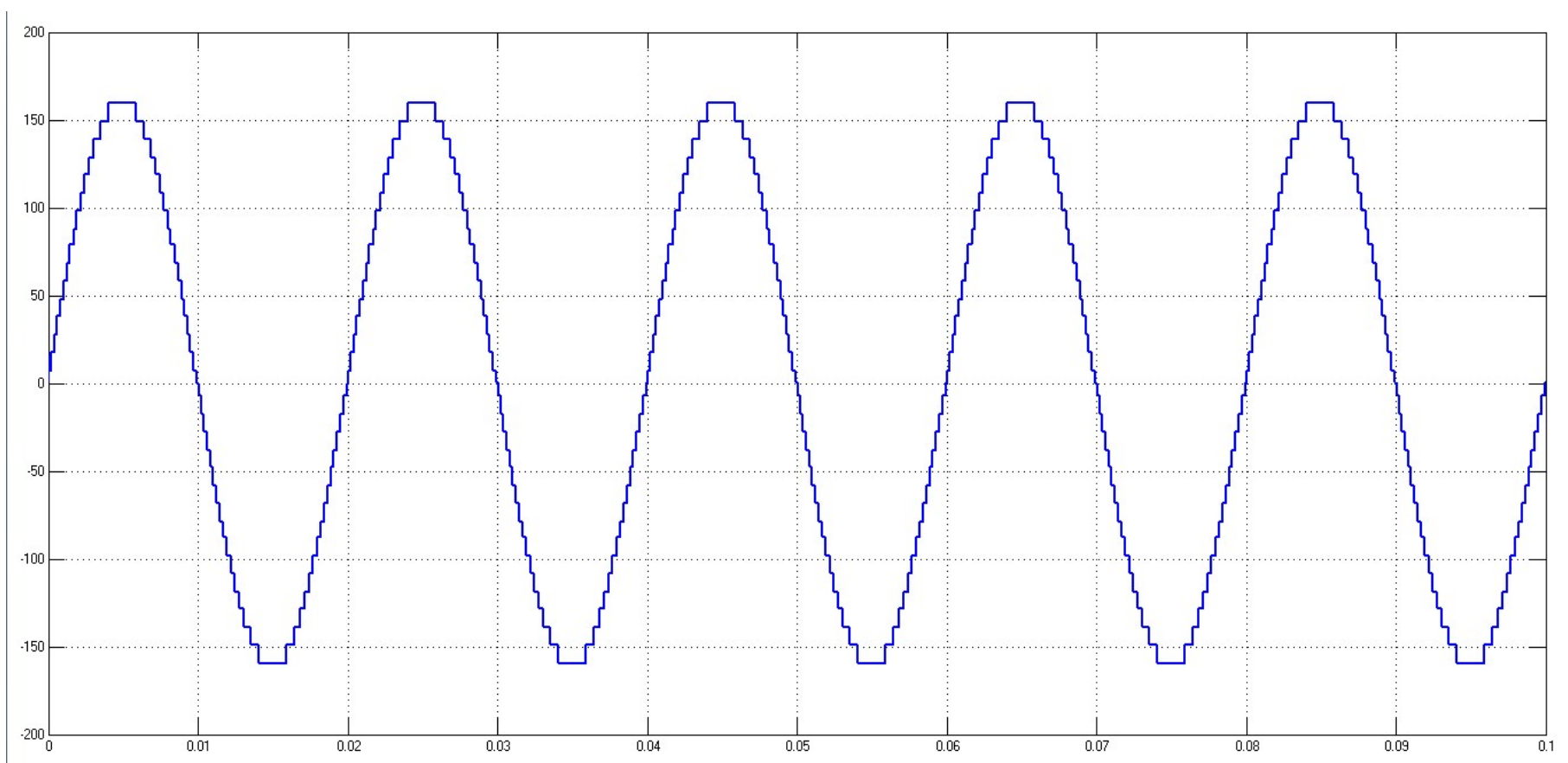

Fig.5. Output voltage waveform of $33-$ level ( $y$-axis $=50 \mathrm{~V} / \mathrm{div} . \mathrm{x}-\mathrm{axis}=10 \mathrm{~ms} / \mathrm{div}$.) 


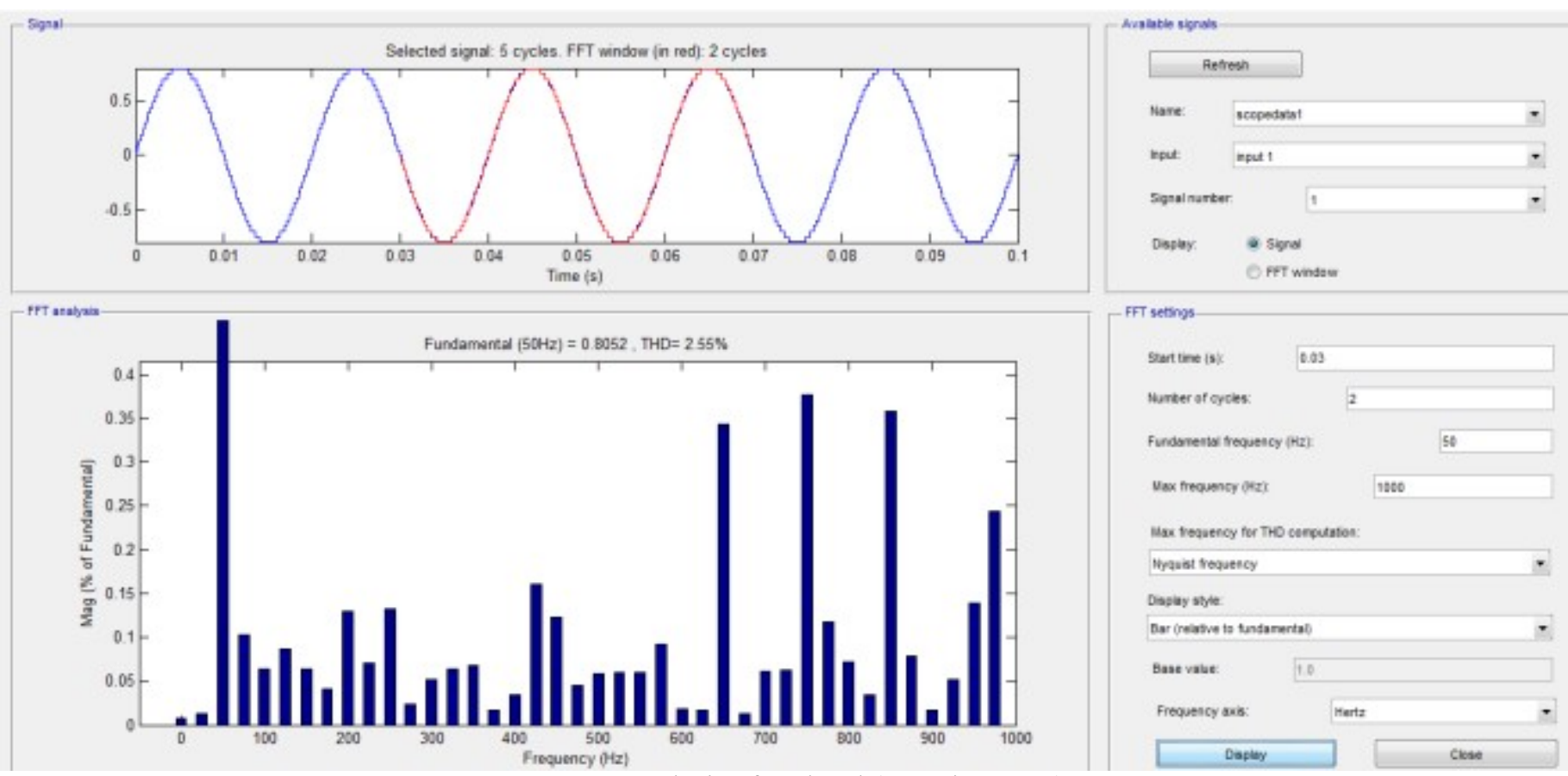

Fig.6. FFT analysis of 33-level (THD is $2.55 \%$ )

The THD of 33-level hybrid MLI is within the IEEE standard as shown in figure 6 [12].

\section{CONCLUSION}

In this paper the simple switching technique is implemented with this natural method of calculation of switching angles we can easily find the best switching angles. No need of solving complex non-linear equations and without writing the MATLAB program for GA and NR. No need of assuming initial angles. With this equal area criteria technique we achieved $2.55 \%$ THD with resistive load for 33-level.

\section{REFERENCE}

[1]. Josérodríguez, Jih-Shenglaifang, Zheng Peng, IEEE Transactions On Industrial Electronics, Vol. 49,No.4August-2002.

[2]. Mahdi Toupchi Khosrhahi, IET Power Electronics 2014, Vol. 7, Iss. 12 pp. 2914-2924.

[3]. Damoun Ahmadi, Ke Zou, Cong Li, Yi Huang, and Jin Wang, IEEE Transactions On Power Electronics, Vol. 26, No. 10, October 2011.

[4]. Kiruthika. P, Ramani. K 2nd International Conference On Eletronics And Communication System-2015.

[5]. Ilhami Colak, Ersan Kabalci and Gokhan Keven, 4th International Conference on Power Engineering, Energy and Electrical Drives, 13-17 May 2013.

[6]. Jagdish Kumar, Biswarup Das, and Pramod Agarwal, Fifteenth National Power Systems Conference, IIT Bombay, December 2008

[7]. Prashanth L Gopal, F.T Josh International Journal of Engineering and Advanced Technology ISSN: 2249 - 8958,

Volume-2, Issue-3 Feb-2013.
[8]. Damoun Ahmadi, Ke Zou, Cong Li Yi Huang, and Jin Wang, IEEE Transactions On Power Electronics, Vol. 26, No. 10, October 2011.

[9]. Maha G. Elsheikh, Mahmoud A. Sayed, Mahrous Ahmed and Mohamed Orabi, IEEE Transaction -2012.

[10]. Dhananjaya. Mudadla, Sandeep. N, G. Ramarao International Conference on Computation of Power, Energy, Information and Communication-2015.

[11]. T V V S Lakshmi, Noby George, Umashankar S, and Kothari D P, International Conference on Power, Energy and Control-2013.

[12]. V S Prasad rao K, P Sudha Rani, Gandham Tabita, Power and Energy Systems Towards Sustainable Energy PESTSE-2014. 